

\title{
Avaliação de políticas públicass nas economias dependentes: uma proposta metodológica
}

\author{
Evaluation of public policies in dependent \\ economies: a methodological proposal
}

\author{
Eduardo Remetente Graciano Geque* \\ Renata La Rovere** \\ Nivalde José de Carstro***
}

\begin{abstract}
Resumo
O estudo da avaliação de políticas públicas nas economias dependentes foi desenvolvido com o intuito de analisar as metodologias usadas para a avaliação das políticas públicas nessas economias, através da revisão da literatura. O estudo reforça a ideia de que tanto as metodologias positivistas, como as pós-positivistas da avaliação de políticas são importantes na avaliação de políticas públicas, pelo enfoque diferenciado que cada uma delas faz. Em segundo lugar, propõe que nas economias dependentes o avaliador esteja atento para apurar se não houve influências externas no ato da tomada de decisão sobre as políticas públicas, o que neste estudo se denominou relações informais de poder.
\end{abstract}

Palavras-chave: Políticas públicas, avaliação de políticas públicas, desenvolvimento e "relações informais de poder".

\begin{abstract}
The study of the evaluation of public policies in dependent economies was developed with the purpose of analysing the methodologies used for an evaluation of the public policies in these economies, through aliterature review. The study reinforces the idea that both positivist and post-positivist methodologies of policy evaluation are important in the evaluation of public policies, because of the differentiated approach that each one makes. In the other hand it calls attention that in dependent economies the evaluator should take into account whether there were external influences in the decision-making of public policies, which in this study are called "informal relations of power".
\end{abstract}

Keywords: Public policies, evaluation of public policies, development and informational relations of power.

\footnotetext{
* Mestre em Desenvolvimento agrário. Candidato a doutor, Universidade Federal do Rio de Janeiro. E-mail: eduardogeque@gmail.com

** Professora do Instituto de Economia da Universidade Federal do Rio de Janeiro.

E-mail: renata@ie.ufj.br

*** Professor do Instituto de Economia da Universidade Federal do Rio de Janeiro.

E-mail: nivalde.castro@gmail.com
} 


\section{INTRODUÇÃO}

A avaliação de políticas públicas tornou-se, nas últimas décadas, um instrumento importante na planificação do desenvolvimento dos países. Porém, alguns Estados economicamente dependentes de poupanças externas resistem sobre a necessidade de avaliação das políticas públicas. Estaresistência pode ser justificada pela consciência de não haver resultados plausíveis a serem mostrados, resultantes da implementação dessa política. Nesta perspectiva, a avaliação de políticas públicas é assumida como controle e prestação de contas, e não um instrumento de planificação. Para dissipar esse provável equívoco, este artigo apresenta uma sugestão metodológica para a análise e avaliação de políticas públicas em países economicamente dependentes. $\mathrm{O}$ artigo começa por debater a avaliação das políticas, distingue os tipos de avaliação de políticas públicas e, em seguida, descreve as relações de poder que podem ocorrer na implementação de políticas públicas nas economias dependentes.

\section{AVALIAÇÃO DE POLÍTICAS PÚBLICAS}

A avaliação é um processo sistemático de coleta e análise de dados, e não um processo desorganizado, de opiniões aleatórias de um programa, estratégia, política ou organização. Trata-se de um elemento crítico para programas e projetos de sucesso. Por essa razão, os objetivos da avaliação são o caminho através do qual se chega ao conhecimento dos resultados ou impacto do projeto, assim como o processo através do qual ele foi implementado (Crumpton et all., 2016; First Nations Development Institute, n.d.; W.K.K. Foundation, 2017). Desta feita,a pesquisa avaliativa pode ser entendida como um conjunto de instrumentos para a mudança que não apenas mostram os problemas ou propõem soluções aos problemas identificados, como também apontam mudanças que podem conduzir ao desenvolvimento da política e do programa (Crumpton et al., 2016). Portanto, a avaliação de políticas públicas é um meio através do qual se pode aumentar a eficiência nos gastos públicos, qualidade de gestão e controle social da eficácia da ação dos governos e não um fim em si mesmo. Existem avaliações ex-ante, contínuas (monitoramento) e ex-post (Secchi, 2013). Este estudo não se debruça sobre cada um destes tipos de avaliação. A sua discussão está centrada nos paradigmas avaliativos que orientam aqueles tipos de avaliações. A discussão nesse sentido é importante porque os seus resultados são diferenciados e contribuem de diferentes formas para a avaliação do programa ou do projeto, a partir de diferentes ângulos.

A Fundação W.K. K. distingue entre avaliação em si e o pensamento avaliativo. Enquanto a avaliação serve para facilitar o processo de aprendizagem e melhorar a estratégia da iniciativa ou do programa, opensamento avaliativo é uma forma de pensamento sobre que resultados são esperados, como os resultados podem ser alcançados e que dados ou evidências são necessárias para munir as futuras ações 
para melhorar os resultados. Fundamenta-se no diálogo, reflexão, aprendizagem e melhoria. A avaliação deve ser encarada não somente como um inquérito para dele extrair julgamentos, mas como um meio para a compreensão da inserção da política, programa ou projeto na realidade em que está inserido (W.K.K. Foundation, 2017).

Assim sendo, a identificação da necessidade de políticas e programas, incluindo a especificação de problemas sociais e a identificação de lacunas de resposta do governo ou inadequações ao responder a eles, deve ser uma das principais maneiras pelas quais os analistas de políticas e programas auxiliam os líderes governamentais. A avaliação sustenta a habilidade de monitorar e medir a qualidade, paz e direção da mudança a que os indivíduos, comunidades e organizações realizam. Ela o faz gerando sistematicamente conhecimento que pode apoiar na aprendizagem, melhoria da qualidade e bom julgamento na tomada de decisão. A avaliação também pode alinhar a finalidade, a ação e o impacto para garantir que as mudanças de longo prazo no nível social se desenvolvam progressivamente (Crumpton et al., 2016; W.K.K. Foundation, 2017).

No entanto, os profissionais de pesquisa de avaliação geralmente não estão envolvidos no processo político antes da introdução de uma resposta política ou programática a um problema social. Em vez disso, depois de se engajarem para avaliar o desempenho das intervenções políticas e programáticas, devem, por necessidade, realizar uma avaliação retrospectiva da necessidade destas intervenções (Crumpton et al., 2016).

\section{GÊNESE DA AVALIAÇÃO DE POLÍTICAS PÚBLICAS}

A avaliação da eficácia das políticas públicas, programas e projetos, por especialistas, é relativamente recente. A abordagem mais comum nessa análise é da chamada policy science, que se dedica à aplicação de métodos científicos rigorosos para as questões que afetam a governança e o governo.

A introdução da pesquisa avaliativa nos países não é uniforme. As circunstâncias histórico-sociais condicionam a sua introdução. A título de exemplo, ademanda por estudos avaliativos em políticas públicas nos EUA aumentou devido ao boom de investimentos e ao aumento dos dados computarizados durante a segunda grande guerra, aliado ao fato de ter havido aumento do interesse de estudantes das ciências sociais, ciências políticas e econômicas e o rigoroso uso demétodos quantitativos (Crumpton et al., 2016).

É preciso assinalar que a avaliação de programas ou projetos nas economias dependentes está relacionada com a necessidade de prestar contas aos órgãos internacionais de fomento. Como exemplos pode-se lembrar os casos de, Moçambique e Ruanda (Ceneviva e Farah, 2012; International Monetary Fund, 2009). Em Moçambique parece datar dosanos 1980, pois nestes anosagências bilaterais e multilaterais financiaram programas e projetos de desenvolvimento que exigiam a 
prestação de contas dos fundos desembolsados. A primeira avaliação multisetorial em Moçambique foi feita no primeiro quartel dos anos 1990, de onde se identificou a escassezde dados estatísticos importantes sobre indicadores macroeconômicos. Foi assim que em 1996 se criou o Instituto Nacional de Estatísticas (INE), financiado por vários organismos internacionais de fomento, incluindo o Fundo Monetário Internacional (International Monetary Fund, 2009). No Ruanda, o processo avaliativo viria a começar mais tarde. A guerra civil e o genocídio que teve lugar entre 1990 a 1994, fragilizou o sistema estatístico ruandês, ao mesmo tempo que dificultou a ajuda para o fortalecimento do mesmo. Assim, em 2000 o Departamento de Estatística do Fundo Monetário Internacional começou a ajudar a elaboração de estatísticas sobre o país e somente em 2003 estas viriam a cobrir todas as áreas dos indicadores macroeconômicos (International Monetary Fund, 2009).

Nos países desenvolvidos em geral, os especialistas em análise e avaliação de políticas públicas vêm trabalhando em universidades, ONGs e órgãos legislativos desde os anos 1960. Por exemplo, nos Estados Unidos, nesteperíodo, a avaliação ganhou espaço como esforço em fortalecer o sistema de defesa, elaboração de novas leis sobre questões raciais e étnicas de minorias, de responder aos problemas de pessoas com deficiência e às exigências dos programas da Sociedade. Nos anos 1970 a avaliação foiusada para verificar se a educação e as organizações sociais usavam os recursos de forma apropriada e se alcançaram os seus objetivos. Na década seguinte (1980) ajudou a promover a excelência na resposta à competição global. E nos anos 1990 aavaliação foi usada para assegurar qualidade, competitividade e equidade na prestação de serviços. Já no século XXI ela tem sido aplicada a diversas áreas, desde a política de defesa até a tecnologia de mídia social. Além disso, a abordagem metodológica também foi alvo de inovações, com o surgimento de novas abordagens como a avaliação do desenvolvimento e avaliação culturalmente responsiva (Crumpton et al., 2016; W.K.K. Foundation, 2017).

\section{PRINCIPAIS TIPOS DE AVALIAÇÃO DE POLÍTICAS PÚBLICAS}

No ato da planificação da avaliação de um programa ou projeto, osavaliadores são chamados a escolher sobque perspectiva farão a avaliação. Comummente, os avaliadores usam técnicas e pressupostos cognitivos positivistas para desenvolverem o seu trabalho, com recurso ao uso de métodos quantitativos de coletae análise de dados. O modelo positivista de avaliação de políticas públicas é "caracterizado pelo quantitativismo; orientadoao resultado; de realidade estável, dedutível, inferencial e hipotética;busca dos fatos ou causas dos fenômenos sociais"' (Da Silva e Gomes, 2018). Aliás, este é o método que os órgãos internacionais de fomentonão só usam nos seus países, como também o sugerem para a avaliação dos projetos por eles financiados (First Nations Development Institute, n.d.; International Monetary Fund, 2009; W.K.K. Foundation, 2017). A avaliação chamada positivista é aquela que cinge a sua análise 
em métodos científicos rigorosos. Por conseguinte, os objetivos da avaliação devem ser específicos, mensuráveis, alcançáveis, com tempo limite e realizáveis dentro do período do projeto, cuja sigla em inglês é SMART (Specific, Measurable, Attainable, Relevant and Time-bound). Específico, na identificação de resultados a serem alcançados; Mensurável, usando termos quantificáveis e objetivos; Alcançável, dado o prazo proposto e capacidade; Relevante, para o problema / declaração de necessidade identificada; Tempo limite, dentro do período do projeto (First National Development Institute s.d.).

A avaliação de políticas públicas pode ser classificada também em função da maneira como ela pode ser usada para desenvolver ou apoiar políticas e programas públicos: (1) instrumentalmente, quando é usado para orientar políticas e práticas; (2) política ou simbolicamente, quando justifica preferências e ações preexistentes; e, (3) conceitualmente, quando é usado para fornecer novas generalizações, ideias ou conceitos que são úteis para dar sentido ao cenário político. Apesquisa avaliativa desempenha também um papel importante na accountability interna da instituição avaliada (Crumptom, 2016). Ultimamente, tem havido maior preocupação em se produzir conhecimento a partir de avaliações, principalmente entre os avaliadores da área de ciências sociais (Crumpton et al., 2016; Guba \& Lincoln, 2011; Lejano, 2012; Rodrigues, 2008; Spink, 2001).

Além disso, importa observar que a área de avaliação de políticas públicas conheceu diferentes tipos de avaliações que se diferenciaram entre si, tanto do ponto de vista dos objetivos, quanto da metodologia. Em geral, a avaliação começou a ser feita para aferir os seus resultados, com base em teorias científicas de neutralidade e objetividade, como visto anteriormente, tendo evoluído para visões mais compreensivas do processo de implementação do programa ou projeto em análise. Nesta última perspectivaa avaliação é feita por meio de análises mais multifocais que ajudam a esclarecer as razões do sucesso ou insucesso de um programa ou projeto de uma determinada política pública. É daí que surgiu o conceito de avaliação de processos. Esta tenta rastrear todos os tipos de consequências da intervenção, incluindo efeitos pretendidos, efeitos nulos, efeitos perversos e efeitos colaterais, sejam advertidos ou inadvertidos. No entanto, a antiga característica distintiva da avaliaçãode processos é a ênfase nas diversas explicações de quaisquer impactos que estejam sob foco. As avaliaçõesde processo concentram-se em avaliações de políticas ambientais, do ambiente administrativo, social e geográfico. A avaliação é executadaem estreita interação com comissários de avaliação e usuários em potencial, e emprega dados estatísticos, pesquisas e questionários rigorosos, bem como informações produzidas através de técnicas qualitativas de coleta de dados, como entrevistas em profundidade, análise e observação direta através de visitas ao local (Vedung, 1997; Lejano, 2012; Rodrigues, 2008).

A obra de Guba e Lincoln, Avaliação de quarta geração de 2011, é ilustrativa. Ela identifica quatro tipos ou gerações de avaliações': 
1 a geração (medição) - avaliação baseada em determinados indicadores previamente escolhidos. Foi usada pela primeira vez por Rice, em 1897, para avaliar a qualidade ortográfica de alunos, usando a sua pontuação nos testes. Os conceitos de medição e avaliação eram usados como sinônimos. $\mathrm{O}$ avaliador tinha uma função meramente técnica.

2a geração (descrição) - introduzida em 1933 para avaliar currículos escolares, descreve os padrões com base nos pontos fortes e fracos de um programa, em função da política (a disseminada análise FOFA ou SWOT, em inglês).

$3^{a}$ geração (juízo de valor) - o avaliador também se torna julgador da política, mantendo os critérios avaliativos da primeira e segunda gerações, com vários matizes²: modelo de fisionomia de Stake de 1967; de avaliação da discrepância de Provus, de 1971; modelo de insumo/produto (orientado para tomada de decisões); modelos orientados para resultados de Scriven, de 1973; de experimentação social de Boruch, de 1974; Campbell, 1969 etc., e modelos críticos de Eisner, de 1979. Nestes modelos, o juízo de valor do avaliador é considerado elemento fundamental da avaliação (Guba e Lincoln, 2011).

Como refere Crumpton (2016, p. 985),

a avaliação envolve juízos de valor sobre a política implementada e tem o objetivo de fornecer informações que possam melhorar a tomada de decisão pública. Requer a definição dos critérios a serem adotados e o conjunto de atributos ou características da política ou programa a serem avaliados. Os critérios comumente usados são eficiência, eficácia, eficácia / impacto, cobertura, qualidade técnica e científica, satisfação e justiça do usuário. Além da definição de critérios de avaliação, o analista deve considerar a extensão da política ou programa. Inclui um serviço ou sistema? Sua área de serviço é local, municipal, regional ou nacional? A população alvo da política ou programa também deve ser claramente delineada. (...) avaliar é formar um julgamento sobre onde o objeto que está sendo avaliado deve ser colocado em um continuum: mais / menos; muito / um pouco; perto / longe; bom mau; adequado / inadequado; alcançado / não alcançado. Nesta perspectiva de análise, espra-se que as políticas públicas e programas envolvam quatro aspectos: 1) identificação da necessidade de intervenção governamental; consideração da teoria da intervenção e componentes operacionais; 3 ) avaliação da implementação e operação da política ou programa; e, 4) mensuração do impacto da intervenção.

De acordo com as novas abordagens de avaliação de políticas públicas (Guba eLincoln, 2011; Rodrigues, 2008), esses modelos têm limites significativos, pois possuem:

1. tendência ao gerencialismo (avaliação baseada nos gestores);

2. incapacidade de acomodar o pluralismo de valores, pois a avaliação é baseadaem valores do avaliador, porém a ciência não é isenta de valores;

3. excesso no comprometimento e uso de paradigmas científicos de investigação.

De fato, o modelo de avaliação de políticas públicas difundidopelas agências de cooperação bilateral ou multilateral mostra que o foco da avaliação dos projetos 
obedece a critérios metodológicos que focalizam a eficiência, a eficácia e o impacto junto ao público beneficiário de seus programas financiados ${ }^{3}$ (Soares, 1997; First Nations Development Institute, n.d.; Stephanou, 2005; W.K.K. Foundation, 2017).

A nova tendência de avaliação de políticas públicas em ciências sociais é de usar métodos flexíveis de coleta de dados. No padrão de pesquisa ortodoxa, o pesquisadorutiliza a mesma forma de entrevista, para toda aamostra de entrevistados. $\mathrm{Na}$ avaliação deprocessos e de caráter compreensivo, pode-se querer alterar o questionário ou roteiro de entrevista de modo a incluir uma questão explícita sobre umpontoconsideradopertinente, que não havia sido previsto no ato dedesenho da pesquisa avaliativa. Evidentemente, não se pode mais relatar os resultados da pesquisa como inteiramente baseados em uma amostra, por exemplo, de cinquenta indivíduos, em relação à nova questão. No entanto, pode-se ser muito bem capaz de encontrar outras quinze pessoas que verificam o efeito colateral em questão, quando explicitamente perguntado sobre isso. Em muitos casos, esse resultado é muito mais importante do que resgatar a qualidade científica da pesquisa (Vedung, 1997). Um segundo tabu científico que pode ser quebrado em questões de avaliação de processo é constituído pelasamostras pré-selecionadas. Se os avaliadores descobrirem durante a entrevista que uma unidade distinta de análise é especialmente interessante porque, por exemplo, essa unidade reflete conflitos prolongados entre vários atores participantes, então eles podem incluir mais deste tipo de unidade na amostra. O design é variado no caminho, conforme apropriado. Esta técnica é chamada de projetos em cascata, emergentes ou rolantes (Vedung, 1997).

Conforme visto, as avaliações que adotam metodologias de análise quantitativa não explicam o processo através do qual os resultados foram alcançados. Para supriressa lacuna, sugeriu-se o paradigma construtivista de avaliação de políticas públicas. Este modelo avaliativo, também chamado interpretativo ou hermenêutico, é compreensivo e desenvolvido através de um processo interativo e negociado, envolvendo grupos de interesse. O paradigma construtivista não se alinha com a visão positivista da existência de verdades objetivas. Para ele, as realidades são construções sociais, mentais. Portanto, a verdade é subjetiva.

O modelo construtivista é chamado da $4^{a}$ geração. Trata-se de um "modelo de avaliação em que as reivindicações e questões dos grupos de interesse servem como enfoques organizacionais (...) que são implementados de acordo com os preceitos metodológicos do paradigma de investigação construtivista" (Guba e Lincoln, 2011, p. 59). A avaliação construtivista deve enfatizar os grupos de interesse (stakeholders) para: (i) evitar que os seus interesses corram risco de serem preteridos e percam a participação na avaliação da política. Além disso, a inclusão dos grupos de interesse ajuda a confrontar e debater os seus juízos de valor; (ii) garantir que os grupos de interesse não sejam privados dos seus direitos e se tornem suscetíveis à exploração. Por conseguinte, é pertinente que as informações dos diferentes grupos de interesse não sejam compartilhadas com outros grupos, para evitar que estes as usem, por 
exemplo, para promover interesses políticos; (iii) persuadir os usuários das informações contidas nas avaliações a dar a elas maior consideração, pois nelas se encontram posições de vários grupos de interesse, que podem ser levados em conta na definição da agenda da política pública; (iv) ampliar o alcance da investigação avaliativa para que haja maior compreensão do fenômeno, o que permite melhor interpretação. Por isso, avaliações que se centram em objetivos, decisões ou efeitos predeterminados produzem resultados restritos e previsíveis; e (v) permitir que os grupos de interesse se instruam mutuamente, por meio da avaliação. Apesar de as reivindicações dos grupos serem imbuídas de valores subjetivos, a troca de opiniões entre si conduz a um aprofundamento dos problemas de todos os grupos de interesse, o que muitas vezes reforça os argumentos de cada um dos grupos. Por isso, é importante identificar as reivindicações, preocupações e questões dos grupos de interesse e cada um deles deve considerar as recomendações dos outros grupos (Guba e Lincoln, 2011).

A avaliação pós-positivista sugerida por Guba e Lincoln, inicialmente publicada em 1989, foi antecedida pela obra "Parâmetros para análise de políticas - a fusão entre texto e contexto" (Framework for policy analysis - merging text and context) publicada em 1961 por Raul Lejano. Ela foi apoiada também por outros autores, como é o caso da teoria da avaliação democrática de Spink (2001), o modelo da avaliação em profundidade de Rodrigues (2008), entre outros.

Lejano (2012) que aliou o componente hermenêutico no exercício da análise e avaliação de políticas públicas, sugerindo a fusão entre o texto eo contexto, destaca a importância do avaliador na interpretação da realidade e indica mecanismos para evitar interpretações inválidas, como elucida o seguinte trecho:

Ao tentar compreender um texto novo, o leitor tenta 'adivinhar' possíveis significados no que está sendo lido. Tal adivinhação, é claro, não é possível de um ponto de vista completamente neutro e imparcial ${ }^{4}$, porque somos inevitavelmente influenciados por nossas predileções pessoais, treino, histórias e crenças. (...) Testamos ou avaliamos nossas interpretações iniciais do texto buscando consistência com elementos do contexto da situação. (...) pode-se partir do texto para o contexto e ousar o segundo para avaliar ou invalidar determinadas interpretações alternativas. Pode-se ir na direção contrária, do contexto ao texto, buscando-se uma interpretação mais profunda e renovada (Lejano, 2012, p. 122 e 123).

Por sua vez, Spink (2001) aborda o tema da avaliação com o objetivo de discutir a avaliação de programas, projetos e atividades como prática social, e não como prática técnica ou científica. Neste processo, ele chama atenção aos avaliadores (no exercício avaliativo por si designado por democrático) pela necessidade da

disposição dos agentes presentes numa determinada situação darem prioridade à discussão e ao debate coletivo sobre a atribuição de valor (....) e para buscar concretizar uma prática de multideterminação negociada, na qual o poder é redistribuído e barreiras de exclusão e mecanismos de desigualdade são desmantelados. (...) Não há dúvida que será um ambiente caracterizado pela diversidade, mas desde que pessoas possam conversar entre si, será sempre possível contrastar e comparar mesmo usando indicadores diferentes (Spink, 2001, p. 17). 
O quadro 1 compara as características gerais da avaliação positivista com a avaliação construtivista.

Quadro1 - Comparação de avaliação positivista com a construtivista

\begin{tabular}{|l|l|l|}
\hline Tipo de avaliação & Positivista & Construtivista \\
\hline Enfoque & Resultados & Compreensão do processo \\
\hline Objetivo & $\begin{array}{l}\text { Medir a eficiência, eficácia e } \\
\text { o impacto do programa ou } \\
\text { projeto }\end{array}$ & $\begin{array}{l}\text { Compreender o processo da } \\
\text { implementação do programa ou projeto }\end{array}$ \\
\hline Modelo paradigmático & $\begin{array}{l}\text { Confiança em verdades } \\
\text { objetivas }\end{array}$ & $\begin{array}{l}\text { A verdade é subjetiva e, por isso, explora a } \\
\text { subjetividade dos atores envolvidos }\end{array}$ \\
\hline Metodologia & $\begin{array}{l}\text { Predominantemente } \\
\text { quantitativa, uso de } \\
\text { inquéritos }\end{array}$ & $\begin{array}{l}\text { Predominantemente qualitativa, uso } \\
\text { de entrevistas semiestruturadas e em } \\
\text { profundidade (histórias de vida também) }\end{array}$ \\
\hline Fontes de informação & $\begin{array}{l}\text { Oficiais, fornecidos pelo } \\
\text { Estado ou empresa (bases de } \\
\text { dados) e coletados dos atores } \\
\text { envolvidos e impactados pela } \\
\text { intervenção }\end{array}$ & $\begin{array}{l}\text { Atores envolvidos na implementação do } \\
\text { programa ou projeto e todos afetados } \\
\text { direta ou indiretamente pela intervenção }\end{array}$ \\
\hline Categorias analíticas & $\begin{array}{l}\text { Pré-concebidas na concepção } \\
\text { da avaliação }\end{array}$ & $\begin{array}{l}\text { Esboçadas na concepção da avaliação } \\
\text { (provisórias) e definidas com base nos } \\
\text { resultados da avaliação }\end{array}$ \\
\hline Finalidade & $\begin{array}{l}\text { Medir os resultados da } \\
\text { intervenção }\end{array}$ & $\begin{array}{l}\text { Identificar elementos de aprendizado a } \\
\text { partir da compreensão e interpretação do } \\
\text { processo de implementação do programa } \\
\text { ou projeto }\end{array}$ \\
\hline
\end{tabular}

Fonte: elaborado pelos autores

Tal como observa Rodrigues (2008), uma das características marcantes do modelo de avaliação positivista é de analisar os dados com base em padrões pré-estabelecidos, a sua abordagem é linear, testa hipóteses, focaliza a análise na mensuração dos resultados, em função dos objetivos do projeto, relacionando metas/resultados, custos/ benefícios e avaliação de impacto. Com este procedimento, perde-se a oportunidade de se fazer acompanhamento de como a proposta original se efetiva. Ao focar os resultados, este modelo não abre espaço para a crítica da política pública em análise. Sendo assim, há pouca possibilidade para os formuladores e implementadores dos programas e projetos de desenvolvimento refletirem sobre a política em si.

A análise de como decorreu o processo de definição da agenda, formulação da política (incluindo identificação de alternativas e análise de opções), tomada de decisão ou escolha de alternativas, a implementação e a monitoria ajudaria a identificar os prováveis erros da política, que podem ser objeto de reflexão e melhoria para os programas ou projetos subsequentes. À luz disso, as novas metodologias de avaliação de políticas públicas enfatizam a "análise do contexto social, econômico, político, cultural" (Rodrigues, 2008, p. 44).

A avaliação deve, portanto, ser adaptada aos contextos da comunidade que está sendo avaliada e aos resultados importantes identificados pela comunidade. Métodos 
mistos (combinação do método qualitativo e quantitativo) e perspectivas diferentes podem ajudar a capturar a realidade e os resultados experimentados pelos membros da comunidade. Nesse sentido, a avaliação deve incluir múltiplas perspectivas e representação de pessoas que se importam com os benefícios do programa. A história é crucial para processar a avaliação. Os fenômenos a serem explicados são colocados dentro de perspectivas abrangentes e amplas de explicação histórica. As avaliações cujo foco é compreender o processo têm grande importância teórica. Eles podem fazer contribuições para construção de teoria sobre a governança. A avaliação de processos também será útil em contextos de ação política e administrativa. Como as informações sobre os resultados são complementadas com dados sobre como as saídas, os processos intervenientes e a situação circundante, em interação uns com os outros, afetaram os resultados, a avaliação será de maior valor prático para modificar e agilizar os processos de intervenção (Vedung, 1997; W.K.K. Foundation, 2017).

A avaliação culturalmente responsiva reconhece que valores culturais, crenças e contexto estão no cerne de qualquer esforço de avaliação. Projetos experimentais com grupos de controle e tratamento não são mais as únicas ou melhores maneiras de avaliar programas que visam melhorar a qualidade de vida das pessoas. Desenhos experimentais avaliam os efeitos causais de um programa comparando dois grupos de pessoas, em que um grupo recebe a intervenção ("grupo de tratamento") e outro não ("grupo de controle"). Outra abordagem nova sobre o campo da avaliação é a atençãocada vez maior em construir conhecimento a partir dela, como se referiu acima, e enfatizar as habilidades para líderes e colaboradores de organizações sem fins lucrativos, afim de preencherem aos requisitos dos financiadores.Por último, cabe destacar a ênfase dada ao papel do contexto e da cultura (tradições particularmente) histórias e normas de pessoas tradicionalmente excluídas ou oprimidas (W.K.K. Foundation, 2017).

É por essa mesma razão que Rodrigues (2008) dá especial enfoque à análise organizacional, como a estrutura de funcionamento, a dinâmica, relações de poder, interesses e valores que permeiam as instituições envolvidas na elaboração e implementação de políticas públicas. A partir dessa percepção,noartigo intitulado "Propostas para uma avaliação em profundidade de políticas sociais", a autora sugere, conforme o próprio título indica, que a avaliação das políticas públicas seja feita de forma profunda. E para isso deve-se analisar o conteúdo do programa, focando principalmente a formulação da política, as bases conceituais e a coerência do programa; a análise do contexto da formulação da política, tal como sugerido por Lejano (2012) e as trajetórias institucional, temporal e territorial do programa (Rodrigues, 2008).

As propostas avaliativas sucintamente apresentadas acima não podem ser consideradas antagônicas, mas complementares. Mesmo o modelo de avaliação chamado positivista é importante numa avaliação para que se possa quantificar os resultados, ou seja, ele mede os resultados ou o impacto da política implementada. 
As metodologias pós-positivistas devem servir para ajudar na compreensão dos resultados da política quantificados por critérios cientificamente apropriados. Dito de outra forma, o modelo pós-positivista foca a sua análise no processo da implementação da política, descrevendo em que condições os resultados obtidos foram obtidos. A uma avaliação exclusivamente positivista pode faltar a exploração do contexto e da percepção que se teve da política medida por si, do nível decisório para o nível operativo, o que pode contribuir para implementação distorcida da mesma. Por outro lado, a avaliação pós-positivista não pode também deixar de valorizar a mensuração dos resultados da política. Portanto, parece razoável afirmar que a avaliação de políticas públicas deve usar métodos integrados para melhor apurar os resultados e também compreender os efeitos não quantificáveis da política.

Quanto à proposta de avaliação com base na trajetória da política, é importante observar que ela pode capturar elementos importantes. Porém, a sua eficiência é limitada em função das circunstâncias sociopolíticas do local para onde o programa ou projeto é formulado e implementado. Com efeito, Vedung (1997) oberva que ahistória é crucial para processar a avaliação. As coisas a serem explicadas são colocadasdentro de perspectivas abrangentes e amplas de explicação histórica. Nessa ótica, este modelo inclui na sua análise as instituições que elaboram e operacionalizam a política, tendo em consideração o ambiente interno e externo, na sua vertente formal e documentada.

\section{AVALIAÇÃO DE POLÍTICAS PÚBLICAS EM ECONOMIAS DEPENDENTES}

Nas sociedades altamente dependentes, como as da região da África Austral, o modelo de avaliação com base na trajetória da política pode deixar escapar elementos quiçá determinantes dos moldes em que a política é desenhada, implementada e avaliada. Os decisores são frequentemente obrigados a escolher alternativas do agrado dos órgãos internacionais de fomento, mesmo que sejam menos eficientes, o que leva a crer que o seu objetivonão é desenvolver o país beneficiário do apoio, mas sim ter benefícios próprios. Esta atitude constitui, de certa forma, fator de subdesenvolvimento. Por exemplo, quando Moçambique pediu ajuda externa, devido à estiagem na província de Inhambane, em 1983, as Nações Unidas exigiram que os alimentos fossem distribuídos por uma ONG, tendo delegado o trabalho à CARE International. ACARE usou formas de transporte inadequadas, encarecendo o processo mais que o necessário. Ademais, as autoridades moçambicanas não participaram no processo de recrutamento do pessoal e a CARE colocou como gestores do projeto antigos membros do "peace corps", sem nenhuma experiência. Como consequência,

muito mais dinheiro do que o necessário foi utulizado para cobrir custos de transportes. Esse dinheiro poderia ter sido utilizado para comprar mais comida ou para tornar a capacidade de transportes existente mais eficiente e mais forte. Além disso, 
a escolha do modo de transporte causou perdas e roubos e fez com que uma parte mais pequena dos bens alimentares de emergência tenha chegado aos grupos alvo do que teria acontecido se se tivesse escolhido o modo de transporte correcto (Abrahamsson \& Nilsson, 1994).

Apesar da constatação destas anomalias, feita pela missão de avaliação sueca, especificamente sobre o não envolvimento das estruturas políticas moçambicanas, para se constituir uma instituição forte para se obterem melhores resultados, o chefe da US AID, Julius Schlotthauer, disse:

Nunca foi intenção da política externa dos EUA reforçar a administração moçambicana ajudando a formar uma organização estatal nacional para o combate à emergência. Pelo contrário, quando mais depressa essas tentativas corroerem, mais fácil se tornará para os interesses privados e para as ONGs encarregar-se da distribuição da ajuda de emergência e chegar aos grupos alvo (...)(Abrahamsson \& Nilsson, 1994).

De fato, parece que Julius Schlotthauer tem razão. Nunca foi intenção dos EUA desenvolver Moçambique. Quando eles decidiram que a Coreia do Sul se desenvolvesse, criaram mecanismos para alcançarem esse objetivo. Estima-se que em trinta anos (entre 1950 aos anos 1980) deramà Coreia do Sul um montante equivalente ao dinheiro dado a cinquenta e três (53) países africanos em quarenta anos (entre 1957 e 1990) (Moyo, 2009). Além disso, os órgãos internacionais de fomento adotam medidas gerais para todos os países que apoiam. A homogeneização da solução das soluções aos problemas dos países economicamente dependentes reforça a ideia de falta de vontade de desenvolvê-los, por se tratar de circunstâncias socioeconômicas diferentes, como se pode ler em Hanlon (1997, p. 137), citando Soares Nhaca da Organização dos Trabalhadores Moçambicanos (OTM):

O FMI usa o mesmo programa em todo lado porque tenta fazer o mesmo em todo lado - criar a dependência em relação ao Norte (...). O FMI não está a tentar resolver os problemas da fome e do subdesenvolvimento aqui, mas sim a satisfazer as necessidades das economias do Note que estão, elas próprias, a reajustar-se. E dependência permanente significa que o FMI pode sempre determinar as políticas de Moçambique, em pormenor.

A contratação da mão de obra não qualificada dos países de origem dos órgãos internacionais de fomento para trabalhar em projetos dos países beneficiáriosda ajuda é outro fator que contribui para o fracasso dos projetos. Esta atitude foi interpretada pelosmoçambicanos como uma forma destes órgãos exportarem o desemprego dos seus países. Como referemAbrahamsson e Nilsson, (1994, p. 121), "a assistência técnica, prestada à Unidade de Apoio Logístico nos últimos oito anos, foi insuficiente. Ela não deu os resultados devidos, simplesmente porque em muitos casos foram os moçambicanos que deram formação ao pessoal externo em vez do contrário". Portanto, ao condicionarem a ajuda externa à assistência técnica, os órgãos internacionais de fomento abrem vagas de emprego para os seus concidadãos. Por essa razão, estes órgãos criam procura excessiva de assistência técnica, por meio de elaboração de 
projetos complexos que precisam da ajuda de consultores; imposição da assistência técnica como parte integrante dos projetos, para dar informações, supervisionar, exigir prestação de contas, assim como controlar e influenciar o governo; e a insistência em resultados rápidos e exigência de mais contribuição estrangeira para acelerar as coisas (Hanlon, 1997).

Como documenta Hanlon (1997, p. 63)

a composição da assistência técnica mudou consideravelmente depois do estabelecimento do programa de reajustamento estrutural. Enquanto os especialistas estrangeiros no primeiro período a seguir à independência eram maioritariamente cooperantes de baixo-custo para preencher lacunas, colocados sob a administração directa do sector público, hoje são cada vez mais peritos consultores em matéria de políticas, colocados a vários níveis de decisão no sector público para dar orientações mais do que receber instruções do serviço público. Além destes, há o grande número de peritos em projectos financiados pelo doador.

Com isto, é fácil concluir que as políticas dos órgãos internacionais de fomento não têm como objetivo criar oportunidades para o desenvolvimento dos países "beneficiários" (Nipassa, 2009; Pimenta, 2007). Referindo-se aos decisores africanose sobre esta temática, Moyo (2009, p. 7) afirma que "eles são (...) coagidos a fazer as licitações dos governos dos seus doadores - apesar da irrelevância obvia para o contexto local". Este fenômeno leva a crer na existência de um poder invisível que estabelece relações informais de poder, que determina as escolhas do poder político. Sendo assim é importante não somente que o avaliador de políticas, em países pobres, procure entender o peso das relações informais de poder, no desenho da política, o que muitas vezes, não consta em documentos oficiais ou disponibilizados para o público. Através desse rastreio dos inputs da política poder-se-ia aferir que política foi desenhada e para quem efetivamente foi desenhada.

Com estes dados, parece claro que a maior parte das políticas supostamente desenhadas para o desenvolvimento da África e para os países pobres, em geral, serve aos interesses dosórgãos internacionais de fomento. Além disso, permitem também supor que a ineficiência dessas políticas, programas ou projetos não é acidental, mas um objetivo previamente definido. A falta dessa compreensão pode levar a juízos equivocados na hora de avaliar a política, o programa ou projeto, pois são desenhados para satisfazer os interesses dos doadores, em nome de ajuda externa, e é precisamente isso que tem acontecido. Todavia, não restam dúvidas que não é fácil apurar as relações informais de poder, dado que são informações consideradas sigilosas. Além disso, elas podem criar oportunidades para a prática de outros atos ocultos como a corrupção (Bobbio, 1986). De fato, Sacks, (2005, pp. 188s), aponta a corrupção como uma das variáveis importantes na manutenção da pobreza em África "o mundo de fora tem respostas prontas sobre o prolongamento das crises em África. Tudo volta atrás, outra vez e outra vez, devido à corrupção e a má administração". Pela complexidade que as relações informais de poder representam, serão detalhadamente analisadas a seguir. 


\section{RELAÇŌES INFORMAIS DE PODER E AVALIAÇÃO DE POLÍTICAS PÚBLICAS}

Por volta dos anos 1525 o rei bogotáda posterior região da Nova Granada, atual Colômbia, mandou ao seu povo extrair ouro até encher uma casa. Essa decisão tomada pelo rei foi implementada pelo povo que paulatinamente foi enchendo de ouro a casa indicada (Acemoglu e Robinson, 2012). Nesta situação, estamos perante um agente $A$ (o rei) que toma decisões e dá orientações a $B$ (o povo). Hipoteticamente, a decisão tomada por A pode beneficiar a A ou B, ou ainda a ambos. Neste caso, existe uma relação formal entre $A$ e $B$. Esta relação é formal porque $A$ é reconhecido por $B$ como sendo uma entidade legítima para tomar decisões sobre $B$, ou seja, não existe outra entidade com legitimidade de decidir sobre B. Nos nossos dias, a entidade A podeser um rei, nas monarquias como os reinos da Swazilândia e do Lesotho ou um órgão eleito, no caso da maior parte dos países democráticos. Portanto, o poder ${ }^{5}$ de tomar decisão e orientar o povo é inerente ao seu estatuto e é reconhecido pelo povo. Todavia, o agente A pode tomar uma decisão influenciado por outrem ou coagido a tomá-la (como aconteceu com o rei bogotá). A entidade que o influencia ou coage o faz porque não tem legitimidade para agir sobre $B$, ou tomar qualquer decisão sobre ele. Por essa razão, para fazê-lo, socorre-se ao poder que A tem sobre B, para atingir os seus objetivos. Com a intromissão do elemento estranho ao poder, aparece um terceiro elemento, um elemento externo da relação legítima entre $A$ e $B$, que se pode designar agente $E$. Este estabelece uma relação de subordinação do agente $A$, constituindo umpoder invisível.

O poder invisível, tal como concebido por Bobbio, constitui o elemento que age como subgoverno ou criptogoverno, nos regimes democráticos. É o conjunto das ações que violam o princípio democrático de a democracia ser o governo do poder público em público. O poder invisível permite que um soberano autoritário ou uma aristocracia aja clandestinamente para o seu próprio benefício (Bobbio, 1986).

No contexto de avaliação das políticas públicas em economias dependentes, constitui o poder que os órgãos internacionais de fomento têm sobre os governantes dos países beneficiários. Ele é invisível porque não aparece à tona, mas está por detrás das decisões dos governantes (agente A). Numa relação informal de poder, o agente A é obrigado a executar alguma agenda de $\mathrm{E}$ para se beneficiar de algum favor deste. Esse favor pode ser a ajuda externa, para financiar a ação do governo, por exemplo, ou a manutenção do cargo que $A$ ocupa, em casos de subordinação hierárquica ou partidária. Nestes casos, o A satisfaz as exigências de $E$. $O$ agente $E$ tem como agenda beneficiar-se dos bens do Estado de forma ilícita para beneficiar a simesmo e, quando se trata de um doador, ao país de origem, como se viu com a experiência moçambicana. Como se pode observar, a relação que se estabelece entre o agente $\mathrm{E}$ e o agente $A$ não é oficial ou formal em relação ao esperado por $B$, pois para o $B$ a legitimidade do ato de decisão reside exclusivamente em $A$. É esta relação ilegítima entre $E$ e A que aqui 
se chama "relação informal de poder". De fato, o E influencia as decisões de A e este passa a ser mero veículo das decisões de $E$ para B. Em termos concretos, a política implementada não é fruto da decisão de $A$, mas de $E$ que influenciou $A$. O A pode ser influenciado por razões políticas, financeiras ou ideológicas. As influências políticas são comuns em países onde os cargos públicos são ocupados por confiança partidária e não por meritocracia. O tomador da decisão, muitas vezes não tem a liberdade de fazer escolhas de alternativas de acordo com conhecimentos técnicos ou práticos que possui. Ele é instruído a consultar a opinião do seu dirigente partidário que tutela a sua área de atuação ou à entidade que o nomeou. Neste caso, o partido político, passa a ser o agente $\mathrm{E}$, porque interfere na gestão da política pública, programa ou projeto para benefício do partido e não do povo. Desta forma, o partido faz ingerência em assuntos estatais, passando a agir por cima dele. Outro poderque muitas vezes tira autonomia de decisão dos atores é o poder financeiro local (Evans, 2010). Quando este financia a campanha eleitoral de um partido, espera que sua empresa seja privilegiada nos concursos públicos. Assim, financiar uma campanha de um partido é um investimento seguro, com retornos garantidos, pois normalmente as empresas investem em partidos que sabem que vão ganhar. Os funcionáriospúblicos são muitas vezes obrigados a tomar certas decisões, mesmo que não estejam de acordo, para satisfazer a exigência do órgão internacional de fomento, ou empresas domiciliadas no país, pois ao contrário não poderão receber a ajuda que precisam. O caso da CARE International acima descrito mostra com clareza como os representantes das agencias doadoras agem nos países pobres.

Este comportamento dos órgãos internacionais de fomento não acontece somente em Moçambique. Estudos indicam ele é frequentemente identificado na região da SADC, Comunidade para o Desenvolvimento da África Austral (sigla em inglês SADC - Southern African Development Community). Dambisa Moyo em "Dead Aid" escreve que,muitas vezes, as instituições de caridade são criticadas, com alguma justificativa, pela fraca implementação dos projetos de desenvolvimento, altos custos administrativos e pelo fato de que, na ocasião de receber a ajuda, os países "beneficiários" são coagidos a fazer a licitação do governo que irá doar a ajuda, apesar da óbvia falta de relevância para o contexto local (Moyo, 2009).

A história de desenvolvimento de Moçambique constitui um exemplo gritante da predominância de relações informais de poder, em que o poder dos órgãos internacionais de fomentose sobrepõe aos interesses nacionais. Quando nos anos 1980 Moçambique pediu ajuda externa, foi submetido a várias obrigações em nome das reformas estruturais, dentre elas: não empregar cidadãos moçambicanos formados no exterior, principalmente os formados em países socialistas ${ }^{6}$ (Cuba e leste europeu); corte nos salários de funcionários públicos, que empurrou técnicos superiores para níveis muito próximos da pobreza; obrigação de ter em cada setor de atividade financiada por esses doadores e nos diferentes níveis de decisão representantes dos mesmos, em nome da assistência técnica que davam orientações aos verdadeiros 
atores do setor público. Em consequência, vários milhões de dólares serviam para acomodar as mordomias dos consultores da assistência técnica, em viaturas de luxo, casas e altos salários. A título ilustrativo, dos 15,4 milhões de dólares fornecidos para incremento na produção do caju 5,4 milhões foram destinados para a ajuda técnica; dos 35 milhões de dólares recebidos para financiar o projeto de produção de algodão, 10 milhões foram destinados a consultores (7 milhões) e para a assistência técnica (3 milhões)(Hanlon, 1997). Enfim, os órgãos internacionais de fomentoagem com base em interesses próprios e menos como agentes de promoção do desenvolvimento.

A constante intromissão dos órgãos internacionais de fomentona tomada de decisão dos governantes dos países economicamente dependentes fez surgir o debate sobre a necessidade de haver independência na gestão dos projetos. Este debate culminou com a criação do conceito de ownership, entendido como sendo a possibilidade de o receptor da ajuda definir a sua própria agenda e programa político, independentemente das suas fontes de financiamento (Castel-Branco, 2011).

$\mathrm{Na}$ abordagem ownershipista, duas percepções foram desenvolvidas sobre quem deve gozar de autonomia na decisão sobre as políticas públicas: por um lado, os defensores da economia do mercado livre acreditam que tal autonomia deve ser detida pelo mercado. Por outro lado, os apologistas da intervenção do Estado entendem que a autonomia tem de ser do Estado em relação a todo processo da política pública, desde a criação da agenda até o fim do processo (Geque et all., 2018; Nipassa, 2009; Castel Branco, 2011). Nesta perspectiva, parece haver um impasse sobre quem de fato deve gozar de ownership neste processo. Porém, dado que as evidências empíricas mostram que o modelo de desenvolvimento baseado no mercado livre não conduz ao desenvolvimento (entendido como desenvolvimento econômico, social e ambiental), mas que retarda o desenvolvimento das economias em desenvolvimento (Geque, et all., 2018; Castel-Branco, 2011; Studwell, 2013; Nipassa, 2009; Soares, 1997), parece ser razoável aceitar o ponto de vista segundo o qual o Estado deve tomar protagonismo. Portanto, para que as políticas públicas sejam bem sucedidas devam ser protagonizadas pelo Estado, gozando da autonomia da escolha das alternativas possíveis, de acordo com o contexto local. por esta via, garante-se não só a eficiência do processo, como também a possibilidade de responsabilidade aos decisores das políticas públicas. É preciso observarque o fato de o Estado gozar de autonomia na definição das políticas públicas não quer dizer que deva ser ele sozinho a se envolver no processo. Ele deve usar a sua autonomia para junto do mercado e da sociedade em geral definir a agenda das políticas públicas e implementá-las.

Apesar da dependência decisória dos países dependentes em relação aos órgãos internacionais de fomento, ao se fazer a avaliação das políticas públicas de desenvolvimento nessespaíses, a culpa do fracasso não é atribuída ao agente $E$, mas ao A, por ser o executor formal do projeto, apesar de não ter sido ele a tomar as decisões de forma independente. Por essa razão, sugere-se que ao se avaliar uma política pública, num país de economia dependente, se preste atenção na origem da decisão 
tomada, se emanada por atores interessados e envolvidos no processo decisório ou de um agente E estranho ao processo.

Existem tambéminfluências ideológicas, nas quais atomada de decisão é baseada em princípios filosóficos ou religiosos. No setor público predominam mais as influências dos países doadores, das agências de cooperação bilateral ou multilateral e dos partidos políticos (ou personalidades que agem em nome do partido).

Numa análise mais profunda, chega-se à conclusão de que as relações informais de poder podem enfraquecer a capacidade política de um governo, pois o agente $A$ é capturado pelo $E$, determinando-lhe o comportamento o que muitas vezes culmina com fracos resultados do programa ou do projeto(Evans, 2010).

Em conclusão, o conceito de relações informais de poder deve ser compreendido em dupla perspectiva: primeiro como as relações que determinam a subordinação do decisor de políticas públicas e, em segundo lugar, como causa das potenciais implicações das decisões tomadas para as políticas públicas, pois as consequências dessas políticas podem ser benéficas ou nefastas. É preciso notar igualmente que as relações informais de poder nem sempre são nefastas. Entidades experientes numa determinada área podem influenciar na tomada de alguma decisão, baseados na sua experiência e ajudar a tomar decisões mais apropriadas.

\section{CONSIDERAÇÕES FINAIS}

A análise da avaliação de políticas públicas nas economias dependentes feita neste artigo enfatiza, em primeiro lugar, a importância das metodologias tanto positivistas como pós-positivistas de avaliação de políticas públicas, por cada uma delas fornecer informações importantes sobre a implementação da política que nenhuma delas de forma exclusiva pode fornecer. Por outro lado, referindo-se particularmente a economias dependentes, mostra a importância de o avaliador das políticas públicas nestas economias prestar atenção à existência ou não de relações informais de poder que poderão ter determinado as escolhas políticas dos decisores e os respectivos resultados.

A experiência dos países desenvolvidos em usar a avaliação para melhorar o desempenho dos governantes, com base em critérios científicos de aconselhamento (policy science), constitui um elemento a ser considerado pelos decisores das políticas públics das economias em desenvolvimento. Este input deveria ser chamado a intervir (consultado) tanto no ato da avaliação ex-ante, assim como na avaliação ex-post. Na primeira fase indicaria as melhores opções para a implementação da agenda, em conformidade com as circunstâncias sociopolíticas, e no fim do processo para extrair lições a partir dos pontos bem sucedidos e das falhas na implementação do programa ou projeto.

Outro ponto que foi destacado neste artigo é a atenção necessária que o avaliador tem de ter em analisar a existência de relações informais de poder, nos 
países economicamente dependentes, identificando de que lado houve ownership no programa ou projeto avaliado (Geque et all, 2018; Studwell, 2013; Castel-Branco, 2011). Dessa atenção, encontrando-se elementos suficientes, pode-se engendrar um debate sobre a influência dos órgãos internacionais de fomento nos resultados da política, programa ou projeto.

\footnotetext{
Notas

1 Para mais informações sobre as 3 gerações e os problemas neles predominantes, vide Guba e Lincoln (2011) PP. 27 - 46.

${ }^{2}$ No geral, estes modelos enfatizam o juízo de valor do avaliador como fundamental na avaliação. Informações mais pormenorizadas dos modelos enumerados podem ser encontrados em Da Silva e Gomes, (2018, PP. 365ss) disponível em https://bit.ly/31HwC6g. Acesso em: 15 Jun. 2018.

${ }^{3} \mathrm{O}$ first National Institute é uma Organização não Governamental estadunidense, que financia projetos de desenvolvimento para os povos indígenas dos EUA (educação, saúde, arte, cultura, etc.), usa também o modelo positivista de análise de projetos. Além dela, a W. K. Kellogg Foundation também usa metodologia semelhante na avaliação dos seus projetos. Foi fundada em Junho de 1930, por Will Keith Kellogg, para ajudar as crianças vulneráveis a ter um futuro melhor. Porém, esta última incorpora questões históricoculturais nos seus modelos avaliativos.

${ }^{4}$ Sobre este ponto, Becker (1977) diz que o pesquisador sempre se posiciona de um lado da história e que geralmente fica do lado do prejudicado, e nunca em posição neutra. veja-se Becker (1977). H. De que lado estamos? BECKER, H. Uma teoria da ação coletiva. RJ: Zahar, 1977.

${ }^{5}$ Por poder se entenda como a capacidade de influenciar ou impor um comportamento a outrem.

${ }^{6}$ Depois da independência em 1975, o país adotou o sistema socialista e teve apoio deste bloco em alguns projetos de desenvolvimento, incluindo formação de seus quadros. Com a medida do FMI de não os empregar, muitos moçambicanos ficaram desempregados e até hoje a maioria não se enquadrou de forma condigna na sociedade.
}

\section{Referências}

ABRAHAMSSON, H. \& NILSSON, A. Moçambique em transição: um estudo da história de

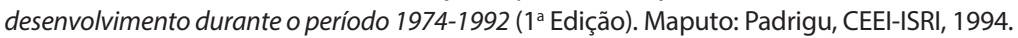

ACEMOGLU, D., \& ROBINSON, J. Por que as Nações Fracassam: as origens do poder, da prosperidadeeda pobreza. São paulo: Elsevier editora Ltda, 2012.

BOBBIO, N. A democracia e o Poder Invisível. In O futuro da democracia: uma defesa das regras do jogo (6a, Vol. 63, p. 171). Rio de Janeiro: Paz e Terra, 1986

CASTEL-BRANCO, C. N. Dependência de Ajuda Externa Acumulação e Ownership: contribuição para um debate de economia política, 2011. Disponível em: www.iese.ac.mz. Acesso em: 15 Jun. 2018.

CENEVIVA, R., \& FARAH, M. F. S. Avaliação, informação e responsabilização no setor público. Revista de Administração Pública, v. 46, n. 4, pp. 993-1016, 2012.

CRUMPTON, C. D., MEDEIROS, J. J., FERREIRA, V. da R. S., SOUSA, M. de M., \& NAJBERG, E. Evaluation of public policies in Brazil and the United States: a research analysis in the last 10 years. Revista de Administração Pública, v. 50, n. 60, pp. 981-1001, 2016.

DA SILVA, A. L., \& GOMES, A. M. Avaliação educacional : concepções e embares teóricos. Estud. Aval. Educ, v. 29, n. 71, pp. 350-384, 2018. Disponível em: http://publicacoes.fcc.org.br/ojs/index. php/eae/article/download/5048/3636. Acesso em: 20 Jul. 2018.

EVANS, P. Constructing the 21st century Developmental State: Potentialities and Pitfalls. In O. Edigheji (Ed.), Constructing a Democratic Developmental State in South Africa Potentials and Challenges (pp. 37-58). Capetown, South Africa: HSRC Press, 2010. 
First Nations Development Institute. (n.d.). Successful Evaluation: Creating SMART Goals and Objectives. Disponível em: https://bit.ly/2ZfsnRC. Acesso em: 20 Jun. 2018.

GEQUE, E. R. G., LA ROVERE, R. L., \& DE CASTRO, N. J. The Evolution of the Public Policy for Sustainable Development in Southern African Development Community: The experience of Mozambique. In Innovation, catch-up, and sustainable development (pp. 1-23). Seoul - South Korea: The International Joseph A. Society, 2018. Disponível em: https://bit.ly/31Ww6Bj. Acesso em: 15 Jun. 2018.

GUBA, E. G., \& LINCOLN, Y. S. Avaliação de Quarta Geração. São Paulo: Editora UNICAMP, 2011.

HANLON, J. Paz Sem Benefício: Como o FMI Bloqueia a Reconstrução de Moçambique. Maputo: Imprensa Universitária- UEM, 1997.

IMF. International Monetary Fund. EVALUATION OF TECHNICAL ASSISTANCE TO POSTCONFLICT COUNTRIES: MOZAMBIQUE AND RWANDA Prepared. Statistics, 1-44, 2009.

LEJANO, R. P. Parâmetros para avaliação de políticas: a fusão de texto e o contexto. São Paulo: Editora Arte escrita, 2012.

MOYO, D. Dead Aid: Why aid is not working and how there is a better way for Africa. New York: Farrar, Straus and Giroux, 2009.

NIPASSA, O. Ajuda Externa e Desenvolvimento em Moçambique: Uma Perspectiva Crítica. II Conferência Do IESE - DinâMicas Da Pobreza e Padrões de Acumulação Económica Em Moçambique, v. 36, n. 22, 2009. Disponível em: https://bit.ly/2L2ALea. Acesso em: 20 Jun. 2018,

PIMENTA, C. Apontamentos Heterodoxos Sobre a Globalização e Desenvolvimento em África. In Conference paper $n^{\circ} 31$ (p. 46). Maputo: IESE, 2007.

RODRIGUES, L. C. Propostas para uma avaliação em profundidade de políticas públicas sociais. ARTIGOS INÉDITOS, 8-15, 2008. Disponível em: http://repositorio.ufc.br/bitstream/ riufc/22510/1/2008_art_Icrodrigues.pdf. Acesso em: 15 Jun. 2018.

SACKS, J. D. The End of Poverty: economic possibilities for our time. New York: The penguin Press, 2005.

SECCHI, L. Políticas Públicas: conceitos, esquemas de análise, casos práticos (2ª). São Paulo: Cengage Learning, 2013.

SOARES, R. P. Avaliação Do Financiamento Do Banco Mundial Ao Programa De Apoio Ao Pequeno Produtor Rural Do Nordeste ( Papp). Rio de Janeiro, 1997. Disponível em: https://bit.ly/33LdRQJ. Acesso em: 15 Jun. 2018.

SPINK, P. Avaliação democrática: propostas e práticas (Fundamento). Rio de janeiro: Assiciação Brasileira Interdisciplinar de AIDS, 2001. Disponível em: https://bit.ly/2ZalMUk. Acesso em: 15 Jun. 2018.

STEPHANOU, M. C. Análise Comparativa das Metodologias de Avaliação das Agências de Fomento Internacionais BID e BIRD em Financiamentos de Projetos Sociais no Brasil. Civitas, 5(1), 127-160, 2005. Disponível em: file:///C:/Users/eduar_000/Downloads/Artigo Banco Mundial.pdf. Acesso em: 20 Jun. 2018.

STUDWELL, J. (2013). How Asia Works: success and failure in the world's most dynamic region. New York: Grove Press, 2013.

Vedung, E. Process Evaluation and Implementation Theory. In Public Policy and Program Evaluation (pp. 209-245). NJ and London, 1997.

W.K.K. Foundation. The Step by Step guide to Evaluation. How to become savvy evaluation consumers. W. K. Kelloggs Foundation, 2017. Disponível em: https://bit.ly/2m7u7qS. Acesso em: 20 Jun. 2018. 